\title{
DESENVOLVIMENTO DE MUDAS DE DUAS ESPÉCIES ARBÓREAS: Mimosa caesalpiniifolia Benth. E Sterculia foetida L. SOB DIFERENTES NÍVEIS DE SOMBREAMENTO EM VIVEIRO
}

\author{
Celene de Albuquerque Câmara*, Laurício Endres** \\ *Bióloga, Mestranda da Universidade Federal de Alagoas - celenec@bol.com.br. \\ **Eng. Agrônomo, Dr., Centro de Ciências Agrárias, UFAL - lauricioendres@pq.cnpq.br. \\ Recebido para publicação: 30/10/2006 - Aceito para publicação: 21/06/2007
}

\begin{abstract}
Resumo
Esse experimento foi conduzido com o objetivo de avaliar o nível de sombreamento necessário à produção de mudas com qualidade para plantio de Mimosa caesalpiniifolia (sabiá), Mimosaceae, e Sterculia foetida (chichá), Sterculiaceae. As mudas foram submetidas aos tratamentos: 0 (pleno sol), 50,70 e $92 \%$ de sombreamento em delineamento experimental inteiramente casualizado com 35 repetições (plantas). Foram avaliados altura da parte aérea, número de folhas, diâmetro do colo, relação de massa seca da parte aérea/raiz, relação altura/diâmetro do colo e comprimento radicular. Em ambas as espécies, as mudas cultivadas sob 50\% de sombreamento apresentaram melhor desenvolvimento vegetativo, com maior diâmetro de colo e desenvolvimento do sistema radicular. Além disso, é sob esse nível de sombreamento que ocorreu o maior acúmulo de massa seca das mudas, principalmente das folhas. Embora a qualidade das mudas tenha diminuído à medida que $o$ sombreamento aumentava, as espécies estudadas apresentaram tolerância a sombreamento de $92 \%$. Palavras-chave: Sabiá; chichá; luminosidade; propagação.
\end{abstract}

\begin{abstract}
Seedlings development of two tree species: Mimosa caesalpiniifolia Benth and Sterculia foetida L., under different shading levels in nursery. This experiment was carried out with the objective to evaluate the necessary shading level to produce quality seedlings of Mimosa caesalpiniifolia (sabiá) and Sterculia foetida (chichá). Seedlings of the two species were submitted to: $0,50,70$ e $92 \%$ shading levels in an entirely random experimental design with 35 replicates (seedlings). The variables evaluated were seedling height, number of leaves and collar diameter; shoot/root dry mass ratio and seedling height/collar diameter ratio. The seedlings cultivated under $50 \%$ shading showed the best development, with higher collar diameter and root development in both species. In addition, at this shading level, the seedlings accumulated more dry mass, mainly at leaves. Although the quality of the seedlings reduced in higher shading levels, these species tolerated up to $92 \%$ shading.

Keywords: Sabiá; chichi; luminosity; propagation.
\end{abstract}

\section{INTRODUÇ̃̃O}

O trabalho com sombreamento consiste, basicamente, na avaliação do crescimento de mudas sob diferentes níveis de luminosidade, visando à compreensão do comportamento e exigência de espécies vegetais ao longo da produção de mudas em viveiro. Várias espécies nativas já foram utilizadas em estudos sobre sombreamento, incluindo muitas espécies arbóreas tropicais (FELFILI et al., 1999; CAMPOS; UCHIDA, 2002; FONSECA et al., 2002; ILLENSSER; PAULILO, 2002; AGUIAR et al., 2005; CARVALHO et al., 2006). Resultados de trabalhos dessa natureza esclarecem o padrão ótimo de desenvolvimento inicial de cada espécie, o que poderá ser aplicado no perfil da área a ser reflorestada, antes da introdução das espécies locais, por exemplo.

$\mathrm{O}$ resultado da ação antrópica sobre o meio ambiente provoca resultados alarmantes, como o resíduo, em média, de apenas $6 \%$ da Floresta Atlântica original. Desse percentual, apenas 2 a 5\% estão em condições de serem preservados. No Nordeste, esse percentual é de apenas 2\% (BARBOSA; THOMAS, 2002).

FLORESTA, Curitiba, PR, v. 38, n. 1, jan./mar. 2008. 
Entre as espécies cultivadas para o reflorestamento de áreas degradadas está o sabiá (Mimosa caesalpiniifolia Benth.), árvore pertencente à família Mimosaceae. Segundo Braga (1976) e Lorenzi (1998), essa espécie é decídua, heliófila, pioneira, seletiva xerófila, característica da caatinga, ocorrendo preferencialmente em solos profundos, tanto em formações primárias como secundárias. Embora seja componente da vegetação da caatinga, é freqüentemente encontrada na Zona da Mata, onde sua madeira é processada e comercializada em grande quantidade. Segundo Pio Correia (1978), o sabiá pode ser recomendado para programas de recuperação de áreas degradadas em regiões secas do Nordeste brasileiro, devido ao seu rápido desenvolvimento.

Outra espécie estudada com o objetivo de reflorestamento é a Sterculia foetida L., pertencente à família Sterculiaceae, conhecida como chichá (SANTOS et al., 2004). Também conhecida com xixáfedorento, é uma árvore que chega a medir 20 metros de altura, possui folhas alternas, flores vermelhas que exalam odor de carne em decomposição, sementes comestíveis, das quais se extrai óleo, e casca e folhas que possuem propriedades diuréticas (Wikipédia, 2007). O chichá é uma árvore ornamental, indicada para arborização de parques e praças, e atualmente tem sido indicada para recomposição de áreas degradadas (LORENZI, 1998).

O objetivo deste trabalho é a avaliação da capacidade de desenvolvimento em viveiro de mudas dessas duas espécies arbóreas, sabiá e chichá, em diferentes condições de sombreamento, visando estabelecer o nível de sombreamento mais adequado à produção de mudas com qualidade para o plantio.

\section{MATERIAL E MÉTODOS}

O experimento foi realizado entre agosto e novembro de 2003, em área aberta não-sombreada, localizada no Sítio Boa Vista (Av. Menino Marcelo, km 04, Serraria), no município de Maceió (AL), situado nas coordenadas $07^{\circ} 35^{\prime} 43.8^{\prime}$ 'S e $45^{\circ} 46^{\prime} 08^{\prime \prime} \mathrm{W}$, em altitude de $60 \mathrm{~m}$.

A identificação botânica do material vegetal foi realizada no Instituto do Meio Ambiente do Estado de Alagoas (Brasil). Uma exsicata de cada espécie encontra-se depositada no herbário desse instituto sob o número MAC22922, para a espécie Mimosa caesalpiniifolia Benth. (sabiá), e sob o número MAC22923, para a espécie Sterculia foetida L. (chichá).

As sementes de sabiá foram colhidas de árvores adultas, com vagens em transição verde-secas, presente em área de mata nas proximidades do local do experimento, localizada nas coordenadas

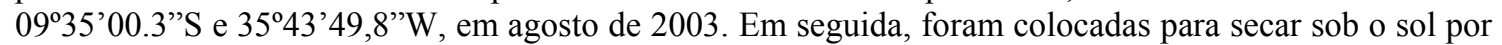
cinco dias, ao fim dos quais foram retiradas das vagens e semeadas em um canteiro de 2 x $3 \mathrm{~m}$, localizado em área com sombreamento natural, fornecido por copa de Syzygium cumini (L.) Skeels (brinco-deviúva). O substrato utilizado para semeadura foi composto de $80 \%$ de terra preta natural, retirada de remanescentes de área de mata localizada no próprio terreno do sítio, e $20 \%$ de esterco de gado curtido.

As mudas de sabiá, quinze dias após a semeadura e com cerca de $5 \mathrm{~cm}$ de altura, foram transferidas para sacos de polietileno preto opacos de $3,5 \mathrm{dm}^{3}(15 \mathrm{~cm}$ de diâmetro e $20 \mathrm{~cm}$ de altura), com furos laterais para drenagem de água (duas mudas por saco).

As sementes de chichá foram colhidas de árvores adultas com frutos secos, presente em área remanescente de mata, situada próxima ao viveiro, nas coordenadas $09^{\circ} 35^{\prime} 43.8^{\prime \prime} \mathrm{S}$ e $35^{\circ} 43^{\prime} 08.1^{\prime \prime} \mathrm{W}$, em setembro de 2003, sendo semeadas nesse mesmo dia, diretamente, nos sacos de polietileno de $3,5 \mathrm{dm}^{3}$ (duas sementes por saco).

A emergência do sabiá iniciou-se sete dias após a semeadura, e a emergência de chichá seis dias após a semeadura. O desbaste das mudas, de ambas as espécies, foi realizado cinco dias após o transplante do sabiá para os sacos plásticos e cinco dias após a emergência das sementes de chichá, deixando-se uma muda por unidade experimental (saco de polietileno).

Foram utilizadas para o transplante em saco plástico plântulas que emergiram no mesmo dia e, portanto, apresentavam o mesmo tamanho.

Os tratamentos empregados constaram de diferentes níveis de sombreamento, a saber:

Tratamento 1 - pleno sol, com mudas expostas em área aberta (controle).

Tratamento 2 - uso de tela sombrite na porcentagem de $50 \%$ de sombreamento.

Tratamento 3 - uso de tela sombrite na porcentagem de $70 \%$ de sombreamento.

Tratamento 4 - mudas expostas a uma condição de baixa luminosidade (aproximadamente 8\%), obtido com as mudas acomodadas sob a copa de Syzygium cumini (L.) Skeels. 
A percentagem de sombreamento sob cada cobertura foi obtida pela razão entre radiação fotossinteticamente ativa (PAR) sob o sombrite e o PAR a pleno sol entre 10:00 e 12:00. A medida do PAR foi feita por meio de um sensor PAR (LCi, ADC, Hoddesdon, UK). A partir da média de dez medidas, obtiveram-se os seguintes percentuais de sombreamento: tratamento $2(62 \%)$, tratamento 3 $(83 \%)$ e tratamento $4(92 \%)$.

Dentro do viveiro, as mudas foram dispostas a uma distância de cerca de $10 \mathrm{~cm}$ umas das outras. As irrigações foram realizadas três vezes ao dia, durante os primeiros 14 dias das mudas, e 2 vezes ao dia após esta idade, até o término do experimento. O turno de rega empregado no experimento possibilitou que as plantas ficassem praticamente todo o tempo em solo sob capacidade de campo.

Quando as mudas de chichá e sabiá atingiram 13 e 24 dias da emergência, respectivamente, foi realizada a primeira medição dos parâmetros de crescimento, que se seguiu em intervalos de aproximadamente 10 dias. Considerou-se como emergência quando as primeiras plântulas emergiram, que para o sabiá iniciou-se sete dias após a semeadura e para o chichá seis dias após a semeadura. Os parâmetros mensurados foram: altura das mudas, número de folhas e diâmetro do colo (obtido na última data de medição para cada espécie). Aos 43 e 62 dias após a emergência, as mudas de chichá e sabiá, respectivamente, foram coletadas e imediatamente levadas ao laboratório do Departamento de Botânica do Centro de Ciências Biológicas, onde foram obtidos o tamanho da raiz (tendo como critério a raiz de maior tamanho), a massa seca da raiz e da parte aérea, a relação de massa da parte aérea/raiz (PA/R) e a relação altura da parte aérea/diâmetro do colo (H/D).

A altura da parte aérea e o tamanho da raiz foram obtidos com régua, e o diâmetro do colo foi obtido com paquímetro. Todas as plantas foram utilizadas na obtenção das massas fresca e seca, com o emprego de uma balança de precisão de 0,01g. A massa seca das plantas foi obtida pela secagem do material armazenado em sacos de papel, em estufa a $70{ }^{\circ} \mathrm{C}$ (BOHM, 1979), onde permaneceram por períodos de 4 dias, aproximadamente.

O delineamento experimental foi inteiramente casualizado, com 35 repetições por tratamento, com uma planta por parcela. Os dados obtidos foram submetidos à análise de variância e as médias comparadas pelo teste de Tukey, a 5 e $1 \%$ de probabilidade.

\section{RESULTADOS E DISCUSSÃO}

Houve variação do diâmetro do colo entre os diferentes tratamentos para ambas as espécies (Tabelas 1 e 2). Da mesma forma, para ambas as espécies, as plantas expostas a 50\% de sombreamento revelaram os valores mais altos quanto ao diâmetro do colo, seguindo-se as expostas a pleno sol. Os menores valores estavam sob $92 \%$ de sombreamento para sabiá e sob 70 e $92 \%$ para chichá. Esses resultados são semelhantes aos encontrados por Aguiar et al. (2005), em que as mudas de Caesalpinia echinata Lam. apresentaram maior diâmetro do caule a pleno sol quando comparadas com as plantas sob sombreamento de 60 e $80 \%$, em todos os períodos de tempo avaliados (12, 18 e 24 meses). Da mesma forma, Felfili et al. (1999) verificaram aumento no diâmetro do colo nas condições de pleno sol e de 50\% de sombreamento para Sclerolobium paniculatum Vog. var. rubiginosum (Tul.) Benth. De acordo com os autores, maiores valores de biomassa e do diâmetro do colo sob esses dois níveis de sombreamento podem ser característica de espécies heliófilas em fases iniciais de sucessão, pois o tratamento a pleno sol pode representar uma condição de área de mata degradada e a condição de sombreamento de $50 \%$ pode representar uma condição de clareira em floresta natural. Almeida et al. (2005) observaram que os maiores valores de diâmetro do coleto ocorreram nas condições de pleno sol e $50 \%$ de sombreamento para a moreira (Maclura tinctoria (L.) D. Don. Ex Steud.), porém, para fedegoso (Senna macranthera (Collad.) Irwin et Barn.), os maiores valores foram encontrados sob condições sombreadas. Com mudas de Trema micrantha L. Blume, Fonseca et al. (2002) observaram que ocorreu decréscimo linear do diâmetro do colo em função do aumento do período de permanência sob sombreamento.

$\mathrm{O}$ número de folhas por planta nas duas espécies (Tabelas 1 e 2) foi obtido no final do experimento, 43 dias após a emergência para chichá e 62 dias para sabiá. Para as mudas de sabiá, o maior número de folhas foi observado em plantas expostas a $50 \%$ de sombreamento (Tabelas 1 e 2 ), havendo uma redução significativa nesses valores em plantas expostas a pleno sol $(\mathrm{P}<5 \%)$ e plantas expostas a $92 \%$ de sombreamento $(\mathrm{P}<1 \%)$. Já para chicha, há uma equivalência entre o número de folhas para os tratamentos de maior luminosidade, pleno sol, 50 e $70 \%$ de sombreamento. De acordo com Campos e

FLORESTA, Curitiba, PR, v. 38, n. 1, jan./mar. 2008. 
Uchida (2002), o número de folhas em mudas de Jacaranda copaiba (Aubl.) D. Don. foi maior sob 30\% de sombreamento. Segundo Faria et al. (2002), o processo fotossintético ocorre principalmente nas folhas, assim, os genótipos que apresentam maior número delas têm maior disponibilidade de fotoassimilados e, conseqüentemente, apresentam maior crescimento.

Tabela 1. Características de qualidade de mudas de Mimosa caesalpiniifolia (sabiá) cultivadas em diferentes níveis de sombreamento, 62 dias após a emergência das plântulas. R: comprimento da raiz $(\mathrm{cm})$; H: altura da parte aérea $(\mathrm{cm})$; D: diâmetro do colo $(\mathrm{mm})$; PA/R: relação entre massa seca da parte aérea e sistema radicular.

Table 1. Quality characteristics of seedlings of Mimosa caesalpiniifolia (sabiá), under different shading levels, 62 days after emergency. R: root length $(\mathrm{cm})$; H: shoot height $(\mathrm{cm})$; D: collar diameter (mm); PA/R: shoot/root dry mass ratio.

\begin{tabular}{lccccc}
\hline $\begin{array}{c}\text { Sombreamento } \\
(\%)\end{array}$ & $\begin{array}{c}\text { Diâmetro do colo } \\
(\mathbf{m m})\end{array}$ & $\mathbf{N}^{\mathbf{0}}$ de folhas & $\begin{array}{c}\text { Tamanho da raiz } \\
(\mathbf{c m})\end{array}$ & $\mathbf{P A} / \mathbf{R}$ & $\begin{array}{c}\mathbf{H} / \mathbf{D} \\
\mathbf{c m ~} \mathbf{~ m m}^{-\mathbf{1}}\end{array}$ \\
\hline 0 & $3,16 \mathrm{ABa}$ & $7,93 \mathrm{Ab}$ & $28,21 \mathrm{Aa}$ & $3,87 \mathrm{Bb}$ & $5,09 \mathrm{Dd}$ \\
50 & $3,60 \mathrm{Aa}$ & $8,71 \mathrm{Aa}$ & $28,36 \mathrm{Aa}$ & $5,62 \mathrm{Bb}$ & $9,59 \mathrm{Bb}$ \\
70 & $2,60 \mathrm{Bb}$ & $8,54 \mathrm{Aab}$ & $25,04 \mathrm{Aa}$ & $8,11 \mathrm{Aa}$ & $15,58 \mathrm{Aa}$ \\
92 & $2,00 \mathrm{Cc}$ & $6,48 \mathrm{Bc}$ & $17,76 \mathrm{Bb}$ & $7,47 \mathrm{ABab}$ & $7,21 \mathrm{Cc}$ \\
\hline
\end{tabular}

Médias na mesma coluna seguidas de mesma letra não diferem entre si pelo teste de Tukey a 5\% de probabilidade (minúsculas) e a $1 \%$ de probabilidade (maiúsculas).

Tabela 2. Características de qualidade de mudas de Sterculia foetida (chichá), cultivadas em diferentes níveis de sombreamento, 43 dias após a emergência das plântulas. R: comprimento da raiz $(\mathrm{cm})$; H: altura da parte aérea $(\mathrm{cm})$; D: diâmetro do colo $(\mathrm{mm}) ; \mathrm{PA} / \mathrm{R}$ : relação entre massa seca da parte aérea e sistema radicular.

Table 2. Quality characteristics of seedlings of Sterculia foetida (chichá), under different shading levels, 43 days after emergency. R: root length $(\mathrm{cm})$; H: shoot height $(\mathrm{cm})$; D: collar diameter $(\mathrm{mm})$; PA/R: shoot/root dry mass ratio.

\begin{tabular}{cccccc}
\hline $\begin{array}{c}\text { Sombreamento } \\
(\mathbf{\%})\end{array}$ & $\begin{array}{c}\text { Diâmetro do colo } \\
\mathbf{( m m})\end{array}$ & $\mathbf{N}^{\mathbf{0}}$ de folhas & $\begin{array}{c}\text { Tamanho da raiz } \\
\mathbf{( c m})\end{array}$ & $\mathbf{P A} / \mathbf{R}$ & $\begin{array}{c}\mathbf{H} / \mathbf{D} \\
\mathbf{c m ~ m m}^{\mathbf{- 1}}\end{array}$ \\
\hline 0 & $5,20 \mathrm{ABa}$ & $6,00 \mathrm{Aa}$ & $27,32 \mathrm{Aa}$ & $1,93 \mathrm{Cc}$ & $2,90 \mathrm{Cc}$ \\
50 & $5,31 \mathrm{Aa}$ & $5,91 \mathrm{Aa}$ & $27,37 \mathrm{Aa}$ & $2,64 \mathrm{Bb}$ & $4,22 \mathrm{Bb}$ \\
70 & $4,77 \mathrm{Bb}$ & $5,85 \mathrm{Aa}$ & $25,65 \mathrm{Aa}$ & $4,28 \mathrm{Aa}$ & $5,77 \mathrm{Aa}$ \\
92 & $4,65 \mathrm{Bb}$ & $4,60 \mathrm{Bb}$ & $17,30 \mathrm{Bb}$ & $4,34 \mathrm{Aa}$ & $3,89 \mathrm{Bb}$ \\
\hline
\end{tabular}

Médias na mesma coluna seguidas de mesma letra não diferem entre si pelo teste de Tukey a 5\% de probabilidade (minúsculas) e a $1 \%$ de probabilidade (maiúsculas).

O tamanho das raízes atingido pelas mudas de sabiá (Tabela 1) e chichá (Tabela 2) diminuíram no tratamento com $92 \%$ de sombreamento $(\mathrm{P}<1 \%$ ), indicando que esse nível de sombreamento, além de influenciar negativamente o crescimento da parte aérea, também tem influência sobre o crescimento do sistema radicular, sugerindo que o processo fotossintético de plantas das espécies estudadas possa ser prejudicado em níveis de sombreamento superiores a $70 \%$.

A relação de massa entre parte aérea e sistema radicular (PA/R) nas plantas de sabiá (Tabela 1) e chichá (Tabela 2) variou de acordo com a exposição às diferentes intensidades de sombreamento. Tanto para o sabiá como para o chichá, o aumento da exposição à radiação fotossintetizante aumenta a partição de assimilados para o sistema radicular (Figura 1). O mesmo ocorreu para mudas de Syagrus coronata (Mart.) Becc., nas quais houve uma tendência de redução na razão de massa raiz/parte aérea no tratamento que recebeu menor nível de luz (CARVALHO et al.,2006). Segundo Bongarten e Teskey, citados por Fonseca et al. (2002), a causa da diminuição do peso radicular sob sombreamento deve-se ao fato de que as mudas produzidas a pleno sol, por estarem sujeitas à restrição hídrica, induzem ao acúmulo de massa seca no sistema radicular, em detrimento do acúmulo de assimilados na parte aérea. Pode-se inferir que talvez a planta esteja preparando-se para condições com maior demanda transpiratória ou condições oligotróficas, nas quais a presença de luminosidade intensa sugere um ambiente com menos nutrientes e água, muito diferente do interior da mata. 

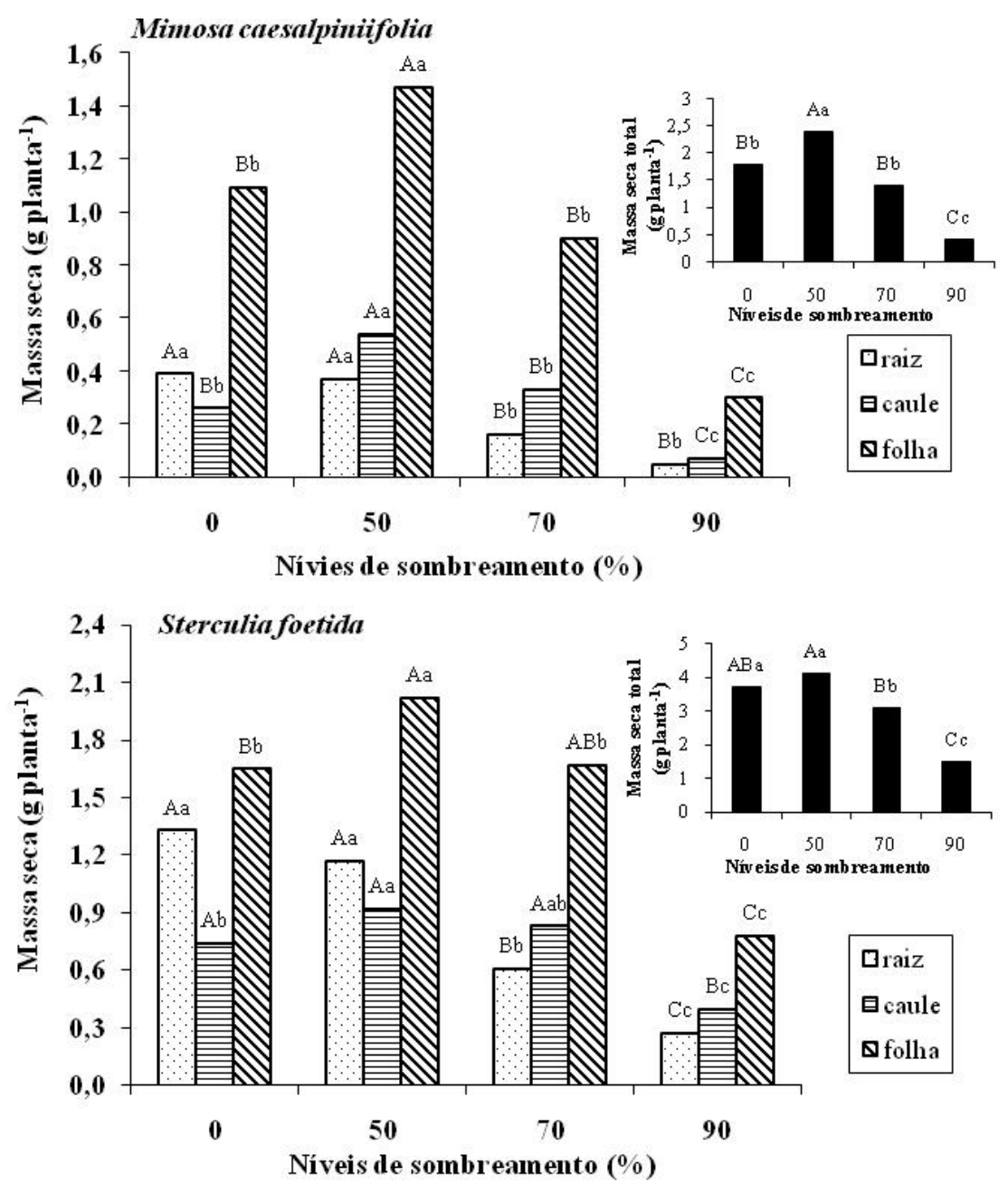

Médias de cada parâmetro analisado (barras de mesma hachura) seguidas de mesma letra, não diferem entre si pelo teste de Tukey a $5 \%$ de probabilidade (minúsculas) e a $1 \%$ de probabilidade (maiúsculas).

Figura 1. Massa seca de mudas de Mimosa caesalpiniifolia (sabiá) e Sterculia foetida (chichá) submetidas a diferentes níveis de sombreamento, aos 62 e 43 dias da emergência das plântulas, respectivamente. Os gráficos sobrescritos correspondem à massa seca total.

Figure 1. Dry mass of seedlings of Mimosa caesalpiniifolia (sabiá) and Sterculia foetida (chichá) submitted to different shading levels, after 62 and 43 days after germination, respectively.

Quanto à relação altura da parte aérea e diâmetro do colo (H/D), tanto sabiá (Tabela 1) quanto chichá (Tabela 2) apresentaram as maiores médias para essa razão sob $70 \%$ de sombreamento, e as menores médias sob o tratamento a pleno sol. Esse resultado é semelhante ao encontrado por Fonseca et al. (2002), segundo os quais, de modo geral, as mudas de Trema micrantha L. Blume apresentaram um aumento linear significativo dessa relação com o aumento do período de permanência sob sombreamento, fato explicado pelo incremento da altura da parte aérea e redução do diâmetro do colo. No trabalho de Campos e Uchida (2002), os resultados encontrados com as mudas de três espécies amazônicas, caroba (Jacaranda copaiba (Aubl.) D. Don.), jatobá (Hymenaea courbaril L.) e pau-de-balsa (Ochroma lagopus Cav. Ex Lam.), que, cultivadas sob $70 \%$ de sombreamento, apresentaram a relação H/D nitidamente superior aos demais, assemelha-se aos resultados encontrados com sabiá e chichá aqui estudados. 
Segundo esses autores, a relação H/D indica a qualidade das mudas a serem levadas ao campo, uma vez que se espera o equilíbrio de seu desenvolvimento. Dessa forma, observaram que as mudas em melhor desenvolvimento não se encontram sob $70 \%$ de sombreamento e sim sob $50 \%$, onde há o equilíbrio na distribuição de fotoassimilados entre as diferentes partes das plantas. $\mathrm{O}$ mesmo pode ser inferido para sabiá e chichá, que apresentaram melhor crescimento a $50 \%$ de sombreamento (Figura 1). Resultados semelhantes foram encontrados por Faria et al. (2002), que estudaram cinco genótipos de Cocos nucifera e verificaram que sob 50\% de sombreamento as mudas apresentaram maior taxa de crescimento.

As mudas de Euterpe edulis Mart., submetidas a uma maior irradiância, apresentaram menor razão PA/R (ILLENSEER; PAULILO, 2002), ao contrario do observado por Fonseca et al. (2002) com mudas de Trema micrantha L. Blume, em que não houve diferença de padrão de partição entre PA/R, independentemente do período de permanência sob sombreamento.

O acúmulo de massa seca pelas plantas (Figura 1) foi observado nas suas diferentes partes: raiz, caule e folhas. Para o sabiá, a maior quantidade de massa seca acumulada pela raiz deu-se nos tratamentos a pleno sol e $50 \%$ de sombreamento. No caule, esse maior acúmulo ocorreu no tratamento a $50 \%$ de sombreamento $(\mathrm{P}<1 \%)$, e para as folhas esse maior acúmulo de massa seca também ocorreu no tratamento de $50 \%$ de sombreamento $(\mathrm{P}<1 \%)$. Semelhantemente ao que ocorreu com mudas de sabiá, mudas de Bombacopsis glabra (Pasq.) A. Robyns produzidas em pleno sol apresentaram maior massa seca da parte aérea (SCALON et al., 2003). Para chichá, a maior quantidade de massa seca acumulada pela raiz deu-se a pleno sol e a 50\% de sombreamento. Para o caule de chichá, esse maior ganho de massa seca foi observado somente em plantas submetidas $50 \%$ e $70 \%$ de sombreamento $(\mathrm{P}<5 \%)$. Quanto às folhas de chichá, o maior ganho de massa seca deu-se nos tratamentos a $50 \%$ de sombreamento $(\mathrm{P}<1 \%)$. Da mesma forma, para mudas de Hymenaea courbaril L., a massa seca das raízes tendeu a acumular-se à medida que houve redução do nível de sombreamento (CAMPOS; UCHIDA, 2002).

Quanto à massa seca total acumulada (Figura 1), o maior ganho deu-se a 50\% de sombreamento para sabiá e, para chichá, a 0 e $50 \%$ de sombreamento. Em ambas as espécies, quanto à massa seca acumulada nas raízes, ramos e folhas e também quanto à massa seca total, as plantas submetidas a $92 \%$ de sombreamento apresentaram as menores médias. A diminuição da taxa fotossintética pela planta pode ter efeito direto sobre o diâmetro do caule e o acúmulo de massa seca, havendo diminuição de seus valores em ambos os casos, sendo que ambas as características são fortes indicadoras de qualidade das mudas. Segundo Fonseca et al. (2002), nas mudas de Trema micrantha L. Blume, houve um decréscimo linear do acúmulo de massa seca da raiz e do caule em função do aumento do período de permanência sob sombreamento.

De forma similar ao observado para sabiá e chichá, no trabalho de Felfili et al. (1999), com plântulas de Sclerolobium paniculatum, também se verificou que houve maior tendência para o investimento de biomassa na parte aérea, em detrimento do sistema radicular, à proporção em que a luz tornou-se menos disponível. Esses autores observaram, ainda, assim como neste trabalho, que a maior produção de massa seca, tanto para a planta inteira como para raiz, caule e folhas, foi obtida quando as mudas estavam sob condição simulando clareira, com cerca de 50\% de sombreamento. Semelhantemente, Almeida et al. (2005) encontraram maior acúmulo de matéria seca foliar para acácia sob pleno sol e para moreira sob 50\% de sombreamento. Segundo Faria et al. (2002), as mudas que apresentam maior massa de parte aérea, têm mais possibilidade de apresentar área foliar maior, o que facilita o estabelecimento inicial das mudas no campo.

Para sabiá, foi observado um aumento na taxa de crescimento em altura das plantas a partir dos 40 dias da semeadura nos tratamentos com 50 e 70\% de sombreamento (Figura 2). Por outro lado, plantas submetidas aos tratamentos de pleno sol e $92 \%$ de sombreamento apresentaram taxa de crescimento relativamente constante (Figura 2). No entanto, plantas sob alta luminosidade investiram mais em tecido de sustentação do que as plantas sob sombreamento intenso (Figura 1), o que pode ser observado pela relação entre altura e acúmulo de massa do caule. Essa relação é de 61,5 e 175,0 cm de altura por grama de caule nos tratamentos pleno sol e $92 \%$ de sombreamento, respectivamente. A altura da parte aérea apresentada pelas mudas de chichá também foi maior a $70 \%$ de sombreamento; já as mudas expostas a pleno sol apresentaram as menores alturas. Quando feita a relação entre altura e acúmulo de massa no caule das plantas, foi observada uma relação de 16,5 e $43,7 \mathrm{~cm} \mathrm{~g}^{-1}$ nos tratamentos a pleno sol e $92 \%$ de sombreamento, respectivamente. Esses resultados sugerem que o sombreamento induz ao estiolamento da parte aérea das plantas, no entanto, sombreamentos muito intensos (92\%) podem inibir o crescimento da 
parte aérea pela falta de fotoassimilados, resultando em plantas com menor acúmulo de massa seca (Figura 1). As plantas estioladas, além de altas e delgadas devido ao alongamento do hipocótilo e dos entrenós, não apresentam coloração verde, pois seus proplastídeos desenvolvem-se em estioplastos, os quais não sintetizam clorofila (TAIZ; ZEIGER, 2004).
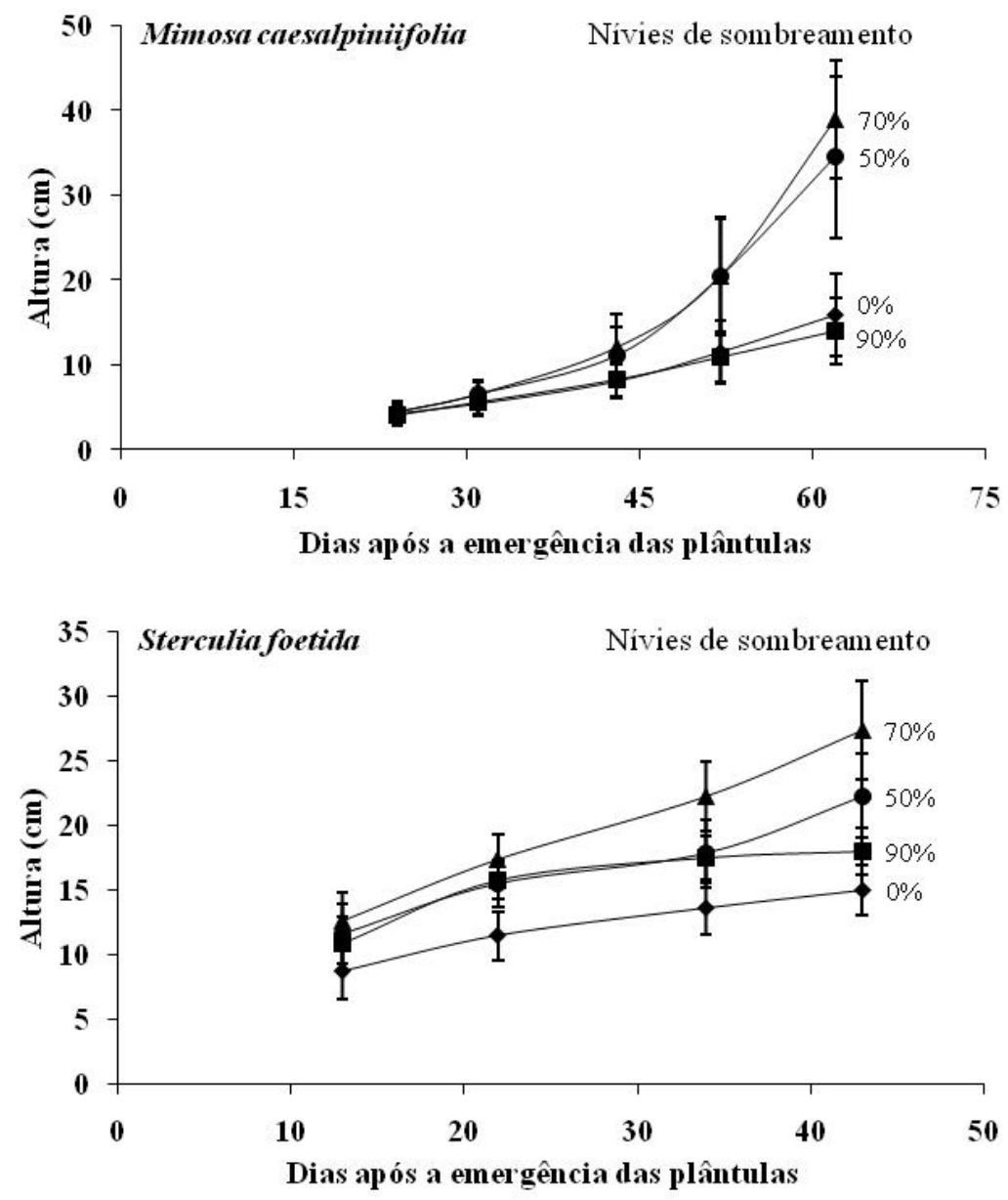

Figura 2. Crescimento de mudas de Mimosa caesalpiniifolia (sabiá) e Sterculia foetida (chichá), após submissão a diferentes níveis de sombreamento.

Figure 2. Height Growth of seedlings of Mimosa caesalpiniifolia (sabiá) and Sterculia foetida (chichá), after submission to different shading levels.

O fato de a taxa de crescimento estar maior, para ambas as espécies, sob $70 \%$ de sombreamento (Figura 2) significa que o crescimento é resultante do acúmulo de fotoassimilados pela parte aérea da planta, principalmente folhas, em detrimento do sistema radicular (Figura 1). Por sua vez, a exposição das mudas a uma alta radiação sugere a alocação de fotoassimilados preferencialmente para o sistema radicular, promovendo maior ganho de massa pelas raízes (Figura 1).

A altura das plantas sob $92 \%$ de sombreamento foi prejudicada nas mudas de sabiá, o que revela uma baixa tolerância dessa espécie para a condição de sombreamento. Já as mudas de chichá revelaram seus menores índices de altura sob pleno sol. No entanto, em ambas as espécies não foram registradas mortes das mudas devido à restrição da disponibilidade de luz. 


\section{CONCLUSÕES}

- Em ambas as espécies, as mudas cultivadas sob 50\% de sombreamento apresentaram melhor desenvolvimento vegetativo, com maior diâmetro de colo e um bom desenvolvimento do sistema radicular.

- Sob 50\% de sombreamento, ocorre o maior acúmulo de massa seca das mudas, principalmente das folhas.

- As plantas estudadas resistem a todos os níveis de luminosidade aos quais foram expostas, desenvolvendo-se com maior ou menor êxito, inclusive quando expostas a pleno sol, mas, também, suportando até a maior condição de sombreamento $(92 \%)$, na qual não foi registrada morte devido à restrição na disponibilidade de luz.

\section{AGRADECIMENTOS}

Os autores agradecem a M.Sc. Rosângela Pereira de Lyra Lemos, pela identificação botânica do material vegetal, à FAPEAL (Fundação de Amparo à Pesquisa do Estado de Alagoas), pelo suporte financeiro da pesquisa, e ao $\mathrm{CNPq}$, pela aquisição dos equipamentos.

\section{REFERÊNCIAS}

AGUiAR, F. F. A.; KANASHIRO, S.; TAVARES, A. R.; PINTO, M. M.; STANCATO, G. C.; AGUIAR, J. de; NASCIMENTO, T. D. R. do. Germinação de sementes e formação de mudas de Caesalpinia echinata Lam. (Pau - Brasil): efeito de sombreamento. Revista Árvore, Viçosa, MG, v. 29, n. 6, p. 871-875, 2005.

ALMEIDA, S. M. Z.; SOARES, A. M.; CASTRO, E. M. de; VIEIRA, C. V.; GAJEGO, E. B. Alterações morfológicas e alocação de biomassa em plantas jovens de espécies florestais sob diferentes condições de sombreamento. Ciência Rural, Santa Maria, RS, v. 35, n. 1, p. 62-68, 2005.

BARBOSA, M. R. de V; THOMAS, W. W. Biodiversidade, conservação e uso sustentável da MataAtlântica no Nordeste. In: Biodiversidade, conservação e uso sustentável da flora no Brasil. Pernambuco: Sociedade Botânica do Brasil: UFRP, 2002. p. 19-21.

BOHM, W. Methods of studying root systems. New York: Springer Verlag; Berlin: Heidelberg, 1979, $190 \mathrm{p}$.

BRAGA, R. Plantas do Nordeste, Especialmente do Ceará. Fortaleza: Escola Superior de Agricultura de Mossoró, 1976.

CAMPOS, M. A. A.; UCHIDA, T. Influência do sombreamento no crescimento de mudas de três espécies amazônicas. Pesquisa Agropecuária Brasileira, Brasília, DF, v. 37, n. 3, p. 281-288, 2002.

CARVALHO, N. O. S.; PELACANI, C. R.; RODRIGUES, M. O. de S.; CREPALDI, I. C. Crescimento inicial de plantas de liricuri (Syagrus coronata (Mart.) Becc.) em diferentes níveis de luminosidade. Revista Árvore, Viçosa, MG, v. 30, n. 3, p. 351-357, 2006.

FARIA, W. S. de; GAIVA, I. X.; PEREIRA, W. E. Comportamento de cinco genótipos de coqueiro (Cocos nucifera L.) na fase de germinação e de crescimento de mudas, sob diferentes sistemas de produção. Revista Brasileira de Fruticultura, Jaboticabal, v. 24, p. 458-462, 2002.

FELFILI, J. M.; HILGBERT, L. F.; Franco, A. C.; SILVA, J. C. S.; RESENDE, A. V.; NOGUEIRA, M. V. P. Comportamento de plântulas de Sclerolobium paniculatum Vog. Var. rubiginosum (Tul.) Benth. sob diferentes níveis de sombreamento, em viveiro. Revista Brasileira de Botânica, São Paulo, v. 22, p. 297-301, 1999.

FONSECA, E de P.; VALÉRI, S. V.; MIGLIORANZA, E.; FONSECA, N. A. N.; COUTO, L. Padrão de qualidade de mudas de Trema micrantha (L.) Blume, produzidas sobre diferentes períodos de sombreamento. Revista Árvore, Viçosa, MG, v. 26, n. 4, p. 515-523, 2002. 
ILLENSSER, R.; PAULILO, M. T. S. Crescimento e eficiência na utilização de nutrientes em plantas jovens de Euterpe edulis Mart. sob dois níveis de irradiância, nitrogênio e fósforo. Acta Botânica Brasílica, São Paulo, v. 16, n. 4, p. 385-394, 2002.

LORENZI, H. Árvores brasileiras: manual de identificação e cultivo de plantas arbóreas nativas do Brasil. Nova Odessa: Plantarum, 1998. v. 1.

PIO CORRÊA, M. Dicionário das Plantas Úteis do Brasil e das Exóticas cultivadas. Rio de Janeiro: Imprensa Nacional, 1978. v. 6.

SANTOS, T. O.; MORAIS, T. G. O.; MATOS, V. P. Escarificação mecânica em sementes de chichá (Sterculia foetida L.). Revista Árvore, Viçosa, MG, v. 28, p. 1-6, 2004.

SCALON, S. de P. Q.; MUSSURY, R. M.; RIGONI, M. R.; FILHO, H. S. Crescimento inicial de mudas de Bombacopsis glabra (Pasq.) A. Robyns sob condição de sombreamento. Revista Árvore, Viçosa, MG, v. 27, n. 6, p. $753-758,2003$.

WIKIPÉDIA. A enciclopédia livre. Disponível em: <http:/pt.wikipedia.org/wiki/Xix \%C3\%A1fedorento $>$. Acessado em: 11/04/2007. 